\title{
The safety of anti-epileptic drug regimens: a qualitative study of factors determining the success of counselling women before conception
}

\author{
Sarah Pashley, Michael F O’Donoghue
}

\begin{abstract}
Background and methodology It is our experience that women who are already pregnant are commonly referred to our service for advice about the safety of anti-epileptic drug regimens. We know of no study that explores why epilepsy-specific preconception advice may be suboptimal. Women who had been referred to the epilepsy service before or during their most recent pregnancy were invited for interview. A thematic analysis of the interviews was used to compare the factors in women who planned their pregnancies with those who did not.
\end{abstract}

Results Over half the women had an unplanned pregnancy and most considered they had received inadequate advice from primary care. Women with planned pregnancies sought out information, perceived the teratogenesis risks as more threatening, and were proactive in seeking a safe pregnancy. Women with unplanned pregnancies seemed less threatened by the risks of teratogenesis, experienced more social disadvantage, were more likely to have misunderstandings about epilepsy and pregnancy, and were vulnerable to deficiencies in primary care epilepsy management.

Discussion and conclusions The success of counselling was determined by a combination of access to care, and the attitudes and social context of women. Identifying those women at risk of unplanned pregnancy and tailoring counselling and treatment to their needs may reduce adverse pregnancy outcomes.

Keywords epilepsy, preconception counselling, pregnancy, primary care

J Fam Plann Reprod Health Care 2009; 35(3): 153-156 (Accepted 9 January 2009)

\section{Introduction}

Between 3 and 6 births in every 1000 are to women with epilepsy. ${ }^{1}$ Seizures and anti-epileptic drugs (AEDs) have the potential to cause harm to the developing infant. ${ }^{2}$ Guidelines advocate a proactive approach to preconception planning in women with epilepsy. ${ }^{3-5}$ However, many women remain only partly aware of the issues, 6,7 They may fail to recall what advice they received. ${ }^{8}$ Studies have focused on the quantity of information women receive, rather than assessing why counselling may fail. We sought to understand why some women with epilepsy are referred to epilepsy clinics already pregnant. We used a thematic analysis of in-depth interviews with women who took AEDs, and had experienced at least one pregnancy, to determine what factors influenced outcome. We use a definition of 'planned pregnancy' that specifies those steps a woman with epilepsy should take before pregnancy to minimise harm to the infant. This definition avoids the complex and fluid notion of whether the pregnancy was intended. ${ }^{9-11}$

\section{Methods}

\section{Design}

In-depth interviews about preconception counselling before the pregnancy were carried out in women treated for epilepsy who had experienced at least one pregnancy. The interviewer (SP) had not been involved in care of the women at the time of the pregnancy. Women were split into two groups for the analysis: 'planned' and 'unplanned' pregnancy. A planned pregnancy was defined as: (1) the

Nottinghamshire Healthcare NHS Trust and Department of Neurology, Nottingham University Hospitals, Nottingham, UK Sarah Pashley, RNMH, MSc, Epilepsy Specialist Nurse

Michael F O'Donoghue, MD, MRCP, Consultant Neurologist

Correspondence to: Ms Sarah Pashley, Department of Neurology, D Floor, West Block, Nottingham University Hospitals, Queens Medical Centre, Derby Road, Nottingham NG7 2UH, UK.

E-mail: sarah.pashley@nottshc.nhs.uk

\section{Key message points}

- Successful epilepsy counselling requires more than just information provision.

- Women in situations of social disadvantage may not consider teratogenesis as much of a threat, and are vulnerable to deficiencies in epilepsy management.

- We need to develop more effective counselling strategies for women with epilepsy.

woman had received advice (before the most recent pregnancy) about epilepsy and AEDs in primary or secondary care, (2) AEDs had been reviewed with pregnancy in mind and any change in treatment had been completed before conception and (3) folic acid $5 \mathrm{mg}$ daily was taken preconception. An unplanned pregnancy was defined as one that failed to meet all these criteria. A review of primary care and hospital medical records documented what was recorded about advice. Signed consent was obtained from all participants.

\section{Participants}

A database held by the epilepsy service of the authors' institution records all adults from 2000 onwards with a diagnosis of epilepsy, and whether a pregnancy has occurred. All women with epilepsy prescribed AEDs who had conceived between 2001 and 2005 were invited for interview. Women in this study had been referred to the clinic either before, or during, the most recent pregnancy. Women were excluded from the study if they were not prescribed AEDs at conception or if they had since moved to another part of the country.

\section{Interviews}

Open-ended questions, derived from clinical knowledge and a literature review, were drafted into an interview guide. A pilot interview was conducted to check feasibility and these data were not used. The interview topics included: (1) what influenced timing of recent pregnancy including steps taken by the participant to plan a safe 
Table 1 Demographics of the study population $(n=37)$

\begin{tabular}{lll}
\hline Characteristic & $\begin{array}{l}\text { Participants } \\
(\boldsymbol{n}=\mathbf{1 5})\end{array}$ & $\begin{array}{l}\text { Non-participants } \\
(\boldsymbol{n}=\mathbf{2 2})\end{array}$ \\
\hline Mean age (years) & 31.5 & 29.0 \\
Epilepsy type & 9 & 12 \\
$\quad$ Focal & 6 & 9 \\
$\quad$ Generalised & 0 & 1 \\
$\quad$ Uncertain & 3 & 2 \\
Seizure-free & & \\
Treatment & 8 & 16 \\
$\quad$ Monotherapy & 7 & 6 \\
$\quad$ Polytherapy & 12 & 7 \\
Married & & \\
Employment status & 8 & 4 \\
$\quad$ Employed & 6 & 10 \\
$\quad$ Unemployed & 0 & 7 \\
$\quad$ Unknown & 1 & 1 \\
$\quad$ Housewife & 9 & 5 \\
Folic acid preconception & 5 & 12 \\
Co-morbidity & 5 & \\
\hline
\end{tabular}

pregnancy, (2) emotions on discovering pregnancy, (3) advice obtained from general practitioner (GP) and hospital clinic before pregnancy and (4) what advice would have been helpful in planning a pregnancy.

Interviews were not constrained by the schedule. Interviews, averaging 60 minutes, were conducted in patients' homes, audio taped, and transcribed verbatim. Primary care and hospital medical records were reviewed for each woman after interview. The transcribed data were coded and analysed independently by the authors, using thematic content analysis. ${ }^{12}$

\section{Ethical approval}

Ethical approval for the study was obtained from the North Nottinghamshire Research Ethics Committee.

\section{Results}

\section{Participants}

Forty-seven women with definite epilepsy who had conceived between 2001 and 2005 were recorded on the database. Ten women were excluded from participation: six were not taking AEDs at conception, three had moved out of the area, and one had died. Thirty-seven women with epilepsy taking AEDs were invited to participate and 16 (43\%) agreed. One respondent moved prior to interview, thus 15 women were interviewed (Table 1). Nonparticipants were more likely to be unemployed and less likely to be married or to have taken preconception folic acid. Three participants were seizure-free. Seven of the 15 women had planned pregnancies (henceforth abbreviated to 'planners') as defined by the study (Table 2). The unplanned group (henceforth 'non-planners') were younger. Non-planners were usually pregnant when referred to the clinic, were more likely to be prescribed two or more AEDs, were usually unemployed, and half had coexisting health conditions.

\section{Thematic analysis}

Thematic analysis of the data generated four key themes: (1) knowledge about epilepsy and pregnancy; (2) attitudes to risks of teratogenesis and pregnancy; (3) action taken in planning a pregnancy and (4) perception of advice before pregnancy. The results are discussed and illustrated with verbatim extracts throughout the text. Numbers in parentheses identify the participants (i.e. UP 1-8, 'nonplanners'; P 9-15, 'planners'). Any text appearing within square brackets are the authors' own words.

\section{Knowledge about teratogenesis and folic acid}

All respondents were aware of teratogenesis associated with AEDs. Planners were able to recall more information. All but one of the non-planners were aware of the need for folic acid, but only two took it, one believing it to be a contraceptive. One woman felt it unnecessary before conception because she knew as soon as she was pregnant: "straight away I know. Straight away I go to the doctors ... I usually buy the folic acid ... I take the normal amount then" (UP2). Planners had more knowledge about folic acid. One, unaware of the need in her first pregnancy, said: "Take folic acid, that was the only bit of advice she [general practitioner] gave me, but obviously subsequently I found out that I needed a higher dose" (P13). This woman had an adverse outcome in her first pregnancy and felt that "Just the advice what it should have been, you know would have been so helpful and the second time round it's so much better and so well prepared. It was a happier time" (P13).

\section{2a. Attitudes to pregnancy planning and fertility}

Five non-planners had at least one other unintended pregnancy (in the conventional sense) and four of these had experienced adverse outcomes (miscarriage or major malformation). Four non-planners were using contraception and all reported contraceptive failures, including two using barrier methods who had three or more failures with this method. One woman taking an oral contraceptive pill commented: "but I will admit I probably forgot some days" (UP5). Two women from the planned group had previous unintended pregnancies (one with a major malformation and one with a difficult pregnancy)

Table 2 Individual characteristics of the study participants

\begin{tabular}{|c|c|c|c|c|c|c|c|c|c|c|c|c|c|c|c|}
\hline \multirow[t]{2}{*}{ Characteristic } & \multicolumn{15}{|c|}{ Participant identification by number } \\
\hline & 1 & 2 & 3 & 4 & 5 & 6 & 7 & 8 & 9 & 10 & 11 & 12 & 13 & 14 & 15 \\
\hline Planned pregnancy & $\mathrm{N}$ & $\mathrm{N}$ & $\mathrm{N}$ & $\mathrm{N}$ & $\mathrm{N}$ & $\mathrm{N}$ & $\mathrm{N}$ & $\mathrm{N}$ & $\mathrm{Y}$ & $\mathrm{Y}$ & $\mathrm{Y}$ & $\mathrm{Y}$ & Y & $\mathrm{Y}$ & $\mathrm{Y}$ \\
\hline Age (years) & 38 & 31 & 22 & 36 & 21 & 30 & 20 & 27 & 36 & 34 & 37 & 32 & 35 & 34 & 39 \\
\hline Married & $\mathrm{Y}$ & $\mathrm{Y}$ & $\mathrm{Y}$ & $\mathrm{N}$ & $\mathrm{N}$ & $\mathrm{Y}$ & $\mathrm{N}$ & $\vec{Y}$ & $\mathrm{Y}$ & $\mathrm{Y}$ & $\mathrm{Y}$ & $Y$ & $\mathrm{Y}$ & $\mathrm{Y}$ & $\mathrm{Y}$ \\
\hline Children $(n)$ & 1 & 5 & 1 & 2 & 1 & 2 & 1 & 2 & 2 & 1 & 2 & 1 & 1 & 1 & 3 \\
\hline Employed & Y & $\mathrm{N}$ & $\mathrm{N}$ & $\bar{N}$ & $\mathrm{~N}$ & $\bar{N}$ & $\mathrm{~N}$ & $\bar{Y}$ & $\bar{Y}$ & $\mathrm{Y}$ & $\bar{Y}$ & $\mathrm{Y}$ & Y & $\mathrm{Y}$ & $\mathrm{H}$ \\
\hline Epilepsy type & $\mathrm{F}$ & G & $\mathrm{F}$ & $\mathrm{F}$ & $\mathrm{F}$ & $\mathrm{F}$ & G & $\mathrm{F}$ & $\mathrm{F}$ & $\mathrm{F}$ & G & $\mathrm{G}$ & G & $\mathrm{F}$ & $\mathrm{G}$ \\
\hline Seizure-free & $\mathrm{N}$ & $\mathrm{N}$ & $\mathrm{N}$ & $\mathrm{N}$ & $\mathrm{N}$ & $\mathrm{N}$ & $\mathrm{N}$ & $\mathrm{Y}$ & $\mathrm{N}$ & $\mathrm{N}$ & $\mathrm{N}$ & $\mathrm{Y}$ & $\mathrm{Y}$ & $\mathrm{N}$ & $\mathrm{N}$ \\
\hline AEDs $(n)$ & 3 & 2 & 1 & 3 & 2 & 2 & 1 & 2 & 1 & 1 & 1 & 1 & 1 & 2 & 1 \\
\hline Folic acid preconception & $\mathrm{N}$ & $\mathrm{N}$ & Y & $\mathrm{N}$ & $\mathrm{N}$ & $\bar{N}$ & $\mathrm{~N}$ & $\bar{Y}$ & $\mathrm{Y}$ & $\mathrm{Y}$ & $\mathrm{Y}$ & $\mathrm{Y}$ & $\mathrm{Y}$ & $\bar{Y}$ & $\mathrm{Y}$ \\
\hline Co-morbidity & $\mathrm{Y}$ & $\mathrm{N}$ & $\mathrm{Y}$ & Y & Y & $\mathrm{N}$ & $\mathrm{N}$ & $\mathrm{N}$ & $\mathrm{N}$ & $\mathrm{N}$ & $\mathrm{N}$ & $\mathrm{N}$ & $\mathrm{N}$ & $\mathrm{N}$ & $\mathrm{N}$ \\
\hline Smoker & $\mathrm{N}$ & $\mathrm{Y}$ & $\mathrm{Y}$ & Y & Y & $\mathrm{U}$ & $\mathrm{Y}$ & $\mathrm{N}$ & $\mathrm{N}$ & $\mathrm{N}$ & $\mathrm{N}$ & U & $\mathrm{N}$ & $\mathrm{N}$ & $\mathrm{N}$ \\
\hline Contraception at conception & $\mathrm{N}$ & $\mathrm{Y}$ & $\mathrm{N}$ & $\mathrm{N}$ & Y & $\mathrm{Y}$ & $\mathrm{N}$ & $\mathrm{Y}$ & $\mathrm{N}$ & $\mathrm{N}$ & $\mathrm{N}$ & $\mathrm{N}$ & $\mathrm{N}$ & $\mathrm{N}$ & $\mathrm{N}$ \\
\hline
\end{tabular}

AED, anti-epilepsy drug; $\mathrm{H}$, housewife; $\mathrm{N}, \mathrm{No}$; U, unknown; $\mathrm{Y}$, Yes.

Epilepsy type: $F$, focal; $G$, generalised. 
that prompted them to seek preconception counselling. One said for her second pregnancy: "I just made sure there were no factors that could cause me to have fits whilst I was pregnant that could hurt the baby" (P15). All planners felt that pregnancy was part of a shared plan with their partner: "well we just thought it was the right time to have a baby" (P13). This was not as apparent in non-planners. At least five of the women had not discussed pregnancy with a partner. Researcher: "Did you discuss having a baby?". Respondent: "No, he just took it [that I was pregnant]. He was all right, fine. That was it" (UP7). An unstable relationship was reported in two of the eight non-planners, and three were not living with a partner at the time of conception. The majority of non-planners had misunderstandings about fertility. Seven seemed genuinely surprised they were pregnant. Four thought they might be infertile as a result of taking valproate or having irregular menses. An underlying belief that they could not conceive may have affected contraceptive practice: "well I'd heard that the Epilim ${ }^{\circledR}$ could make you infertile” (UP7). Irregular menses and not having conceived in the past had strengthened this belief.

\section{2b. Attitudes to the risk of AEDs and pregnancy}

All planners expressed fears about pregnancy. "You're always tinged by a slight concern. Generally it is a time of great happiness and it is for me but always tinged with quite a lot of anxiety" (P11). Another woman said: "I was so petrified of having another one because of all the things I'd had to go through" (P13). Non-planners were less likely to worry about the risks associated with AEDs despite having knowledge. Only two non-planners expressed concerns but went on to say "We were never overly bothered. We was like if it happens, it happens [pregnancy]." (UP1) and "but I never plan [laughing] they just happen ... we had all the other kids and nothing had happened ... and at the end of the day if anything was wrong with him it wouldn't make a difference to me" (UP2). This suggests that past experiences and a degree of fatalism determined responses in non-planners.

\section{Action towards seeking a safe pregnancy}

Women with planned pregnancies were more likely to seek information. All were aware of the national voluntary epilepsy organisations, six had used their services and four were members. Only three women with unplanned pregnancies reported having sought information. Four nonplanners were unaware of any voluntary organisations, and none belonged to one. One non-planner felt that her epilepsy was different from the "main ones" and thus the information on offer wouldn't be helpful to her.

One planner visited her GP for preconception counselling: "I knew what services were available and I insisted" (P13). Six out of seven planners actively sought advice, in comparison to one out of eight non-planners. Five of those who planned instigated the referral to a neurologist. A woman, whose sister told her that valproate could damage her baby, requested referral to a neurologist when 5 weeks pregnant but was not referred until she was 13 weeks pregnant (UP7). Women with planned pregnancies were more assertive and questioning about their condition, for example: "I made the decision come what may I was not going to stay on valproate" (P13). It was clear that the more articulate and determined women were usually successful in finding information, whereas non-planners were vulnerable to poor care. Planners were more likely to be at the centre of any decision-making processes about their epilepsy, preconception planning, and pregnancy, and to feel in control.

\section{Assessment of service provision}

Ten of the women felt their GP had not provided adequate advice before pregnancy. GPs initiated a preconception prescription for folic acid in only two women. Most nonplanners did not seek advice from elsewhere. Most planners asked to see a neurologist. The women identified several factors that they felt would be useful:

- Information should be given at diagnosis

- Two emphasised counselling teenagers "because accidents happen"

- Information should be repeated

- Information leaflets were helpful, but no substitute for discussion

- GPs were identified as having a role in discussing the issue and referring for specialist advice

- Two women said that they had been asked about whether they wanted children and had said that they did not, but had become unexpectedly pregnant.

Fourteen GP records were obtained (consent was not obtained for one set). Relevant advice was recorded in four records (two planners and two non-planners), with a brief account of an epilepsy treatment review in five records. In the hospital records, advice about pregnancy was recorded in $12 / 15$ records. Six women were already pregnant when referred to the epilepsy clinic, and three of these had relevant advice recorded in their paediatric, neurology or obstetric records. The three women without evidence of advice had all been patients of the epilepsy clinic at some stage.

\section{Discussion}

The conclusions are limited by the small sample size and single interviewing time point. Replication of the findings in a larger study and in other areas of the country would be useful. Nevertheless, participants repeatedly raised similar issues suggesting key topics were uncovered. Measures employed to combat the interviewer's preconceptions influencing analysis included reading the medical records after interview, transcribing interviews verbatim and checking of intonation and inflection. A second researcher independently analysed the dataset. We think that agreement between researchers diminished bias. Participants were ethnically homogeneous (Caucasian) and a study undertaken with different ethnic groups would be valuable for comparison.

The women with planned pregnancies demonstrated motivation and resourcefulness. For these women providing timely access to information may be sufficient to achieve successful counselling before pregnancy. Nonplanners were less knowledgeable and vulnerable to deficits in information provision. Psychosocial and economic factors influence the ability to modify behaviour. Family support, in particular from a partner, has a positive influence on ability to make lifestyle changes. ${ }^{13-15}$ Half the women with unplanned pregnancies lacked this support. Poor health knowledge set in the context of social adversity affects perceived internal control, and leads to more passive coping strategies. ${ }^{16,17}$ The markers of social adversity for women in this study were risk factors for unplanned pregnancy, poor compliance or suboptimal care. ${ }^{13,18,19}$ Changing health behaviour, without recognising and addressing the psychosocial and economic environment in which the behaviour takes place, is unlikely to be successful.

There is evidence that the idea of planning a pregnancy is alien to some women, particularly but not exclusively in women from socially deprived areas. ${ }^{9-11}$ The women from poorer backgrounds were more likely to express fatalism, and seemed less likely to consider adverse pregnancy 
outcomes a problem. Further studies exploring how this concept arises may help health professionals motivate patients to seek healthy pregnancy outcomes.

Women lacked confidence in primary care to manage their condition and felt the pressure of limited time during consultations. These perceptions are echoed in other chronic health studies. ${ }^{20,21}$ Evidence suggests that incorporating discussion about epilepsy into routine visits in addition to planned reviews may be a useful approach to encourage patient participation. ${ }^{22}$ Improved outcomes from patient involvement are evident.15,21 This study suggests a dangerous combination for some patients of lack of access at primary care level to preconception epilepsy advice with a personal laissez-faire style, which would seem to encourage adverse pregnancy outcomes. Skilled assessment of women's preferred level of participation in health decision-making should encourage the practitioner to engage external support networks, and adapt the consultation style to suit the patient and promote better understanding and positive behavioural change.

The Quality Outcome Framework review of patients with epilepsy in general practice is an opportunity to discuss contraception and preconception epilepsy advice. Epilepsy-specific advice needs to be given within the context of general preconception counselling. These topics should be included within the existing parameters currently recommended in the review framework. ${ }^{23}$ Practice nurses may be ideally placed to provide reviews with additional training. Epilepsy specialist nurses are a resource that could be used to support practice nurses in meeting this challenge.

\section{Statements on funding and competing interests}

Funding Funding was obtained from the Research Department of Nottinghamshire Healthcare NHS Trust to transcribe the audiotapes.

Competing interests None identified.

\section{References}

1 Fairgrieve SD, Jackson $M$, Jonas $P$, Walshaw $D$, White $K$, Montgomery TL, et al. Population based, prospective study of the care of women with epilepsy in pregnancy. BMJ 2000; 321(7262): 674-675.

2 Yerby MS, Kaplan P, Tran T. Risks and management of pregnancy in women with epilepsy. Cleve Clin J Med 2004; 71(Suppl. 2): S25-S37.

3 National Institute for Clinical Excellence (NICE). The Epilepsies: The Diagnosis and Management of the Epilepsies in Adults and Children in Primary and Secondary Care (Clinical Guideline 20). 2004. www.nice.org.uk/nicemedia/pdf/ CG020 NICEguideline.pdf [Accessed 4 November 2008].

4 Crawford P. Best practice guidelines for the management of women with epilepsy. Epilepsia 2005; 46(Suppl. 9): 117-124.
5 Scottish Intercollegiate Guidelines Network (SIGN). Diagnosis and Management of Epilepsy in Adults. Edinburgh, UK: Royal College of Physicians, 2003.

6 Bell GS, Nashef L, Kendall S, Solomon J, Poole K, Johnson AL, et al. Information recalled by women taking anti-epileptic drugs for epilepsy: a questionnaire study. Epilepsy Res 2002; 52: 139-146.

7 Kampman MT, Johansen SV, Stenvold H, Acharya G. Management of women with epilepsy: are guidelines being followed? Results from case-note reviews and a patient questionnaire. Epilepsia 2005; 46: 1286-1292.

8 Lewis S. Counselling of women with epilepsy on antiepilepsy drugs: the value of nurse led clinics. J Neurosci Nurs 2006; 2: 356-360.

9 Barrett G, Wellings K. What is a "planned" pregnancy? Empirical data from a British study. Soc Sci Med 2002; 55: 545-557.

10 Family Planning Association (fpa). Misconceptions: Women's Attitudes to Planning and Preventing Pregnancy. London, UK: fpa, 2000 .

11 Moos MK, Petersen R, Meadows K, Melvin CL, Spitz AM. Pregnant women's perspectives on intendedness of pregnancy. Womens Health Issues 1997; 7: 385-392.

12 Nowell R. Research for Evidence Based Practice. Oxford, UK: Blackwell Publishing, 2006.

13 Janz N, Herman W, Becker M, Charron-Prochownik D, Shayna $\mathrm{V}$, Lesnick T, et al. Diabetes and pregnancy: factors associated with seeking pre-conception care. Diabetes Care 1995; 18: 157-165.

14 Holing EV, Brown ZA, Beyer CS, Connell FA. Why don't women with diabetes plan their pregnancies? Diabetes Care 1998; 21: 889-895.

15 Stromberg A, Brostrom A, Dahlstrom U, Fridlund B. Factors influencing patient compliance with therapeutic regimens in chronic heart failure: a critical incident technique analysis. Heart Lung 1999; 28: 334-341.

16 Rollnick S, Butler CC, McCambridge J, Kinnersley P, Elwyn G, Resnicow K. Consultations about changing behaviour. $B M J$ 2005; 331: 991-963.

17 Whitehead D. A social cognitive model for health education/health promotion practice. J Adv Nurs 2001; 36: 417-425.

18 Sword W. A socio-ecological approach to understanding barriers to prenatal care for women of low income. J Adv Nurs 1999; 29: 1170-1177.

19 Mayer JP. Unintended childbearing. Maternal beliefs, and delay of prenatal care. Birth 1997; 24: 247-252.

20 Pollock K, Grime J. Patient's perceptions of entitlement to time in general practice consultations for depression: qualitative study. BMJ 2002; 325: 686-692.

21 Caress A, Beaver K, Luker K, Campbell M, Woodcock A. Involvement in treatment decisions: what do adults with asthma want and what do they get? Results of a cross-sectional survey. Thorax 2005; 60: 199-205.

22 Thapar A. Care of patients with epilepsy in the community: will new initiatives address old problems? Br J Gen Pract 1996; 46: 37-42.

23 Department of Health. Quality Outcome Framework Guidance Revisions. 2004. www.dh.gov.uk/en/Healthcare/Primarycare/ Primarycarecontracting/QOF/DH_4125653 [Accessed 4 November 2008].

\section{The safety of anti-epileptic regimens: a qualitative study of factors determining the success of counselling women before conception}

\section{CRITICAL READING QUESTIONS}

Qualitative studies focus on answering the questions "why" and "how".

1 Does this study answer why most women did not think they had received advice about pregnancy and their epilepsy treatment?

2 Did the setting in which the study was conducted influence the conclusions drawn?

3 In the light of this study, how could you change your clinical practice to reduce the number of women being referred for advice on epilepsy treatment after becoming pregnant?

This is a new initiative the journal is trying out for selected articles. The critical reading questions are provided to stimulate thought and discussion, and can be used as a starting point for a journal club meeting. The journal editorial team welcomes feedback from the journal's readers on this new initiative. 